\title{
A Hospital Based Prospective Observational Cross Sectional Study from India to Evaluate the Role of Integrated Management of Childhood Illness (IMCI) in under Five Childhood Illnesses (6 Months to 5 Years)
}

\begin{abstract}
Aim: To evaluate the utility of implementing WHO/UNICEF IMCI algorithm to the childhood illness ( 6 months to 5 years) patients in reducing the morbidity (immediate and long term) and to assess the incidence of childhood illness which are entirely treatable at the first level health care facility.
\end{abstract}

Method and material: This prospective observational cross sectional study enrolled 3200 patients in the age group of 6 months to 5 years. After being registered into the study, each child was thoroughly examined for all the conditions included in the IMCI algorithm, their disease classified, co-morbid conditions and the empirical treatment identified and entered in predesigned performa. The cases were either advised home treatment and followed for 5 days or admitted to the ward and followed up for 5 days after discharge. Consent was taken from all parents before enrolment.

Results: A total of 3200 children attending the outpatient clinic were evaluated, among them 1040 (35.6\%) children were hospitalized and 2160 (64.37\%) were treated as out patients or were referred and followed up. The commonest complaint with which the child was brought to hospital was fever followed by cough and / or difficult breathing. The most common etiology for fever was acute respiratory infection followed by infectious diarrhoea. The overall mortality rate in this study was $1.2 \%$ with pneumonia being the most common cause for mortality.

Conclusion: IMCI can be implicated easily at the hospital level and common IMCI disease can be managed on outpatient basis with regular follow up. With the use of IMCI, the inpatient load can be reduced and unnecessary burden can be reduced. IMCI can be used in referral system so that sickest children can get best and early health care.

Keywords: Integrated management of childhood illness; Child health; Mortality; Fever, Pneumonia

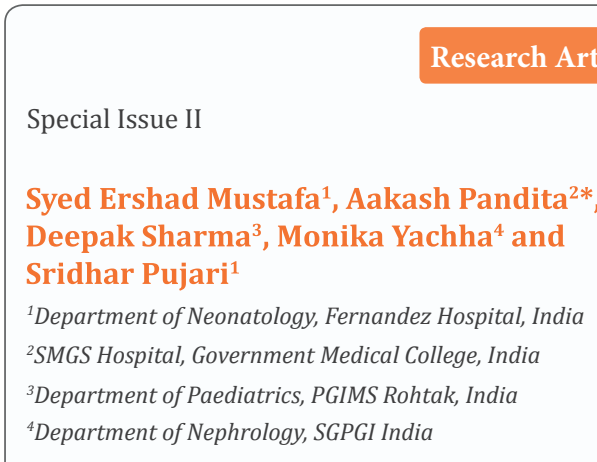

*Corresponding author: Dr. Aakash Pandita, MD, DNB Neonatology, Department of Paediatrics, Government Medical College, Jammu, India, Email:

aakash.pandita@gmail.com

Received: February 20, 2016 | Published: May 13, 2016
Abbreviations: IMCI: Integrated Management of Childhood Illness; WHO: World Health Organization; UNICEF: United Nations International Children's Emergency Fund; ARI: Acute Respiratory Infection; ORS: Oral Rehydration Salts

\section{Introduction}

Integrated management of childhood illness (IMCI) is a strategy developed by WHO/UNICEF, which aims at reducing child deaths and frequency and severity of illness and disability among children in developing countries. It is thought to contribute to improved growth and development by addressing the five major life threatening conditions along with other preventive interventions in one single integrated approach $[1,2]$.
It is estimated that nearly 12 million children die every year in developing countries before reaching their $5^{\text {th }}$ birth day. Under 5 mortality is almost 10 times greater in developing countries than in the richest nations [3]. The major contributors to this high childhood mortality are diseases like pneumonia, diarrhoea, measles and malaria in addition to malnutrition. In a recently published study in the Lancet, the authors reported that among 6.3 million children in 2013 who died before age 5 years, $51.8 \%$ died of infectious causes [4]. IMCI is an effective, low- cost strategy for improving the child health, by focusing on prompt recognition and treatment of all co-existing conditions, rapid and effective treatment through standard case management and prevention of illness through improved nutrition including breast feeding and vaccination $[5,6]$. 
Interventions included in the IMCI Guidelines are [5]

\begin{tabular}{|c|c|}
\hline Case management interventions & $\begin{array}{c}\text { Preventive interventions } \\
\text { Immunization during sick } \\
\text { child visits }\end{array}$ \\
\hline Acute respiratory infections & Nutrition counselling \\
\hline Diarrheal, dehydration & Breast feeding support \\
\hline Persistent diarrhoea & Vitamin "A" supplementation \\
\hline Dysentery & \\
\hline Meningitis, sepsis & \\
\hline Malaria & \\
\hline Measles & \\
\hline Malnutrition & \\
\hline Anaemia & \\
\hline Ear Infection & \\
\hline
\end{tabular}

In present study the disease pattern in children between 6 months - 5 years, attending outpatient clinic, was observed, using the WHO/UNICEF IMCI algorithm, to test the hypothesis that we could reduce morbidity (immediate and long term), and effectively assess the incidence of the most common and treatable childhood diseases.

\section{Method and Material}

Present study included 3,200 patients, 6 months to 5 years of age, attending the outpatient clinic over a 2 year period, from March 2010 to March 2012. This study included those patients who were admitted to the Children's ward from the outpatient clinic after being registered into the study. This study was approved by institutional research board.

Cases were selected from the outpatient clinic in the first week of every month, excluding the public holiday when the outpatient services were not offered. All parents were briefed about the nature of the study and written consent was obtained before enrolment.

\section{Inclusion criteria}

- Children between 6 months to 5 years of age.

- Children who had not received any treatment for the present condition before coming to our hospital.

\section{Exclusion criteria}

a) Children who had received treatment for the present complaint outside our hospital.

b) Parental consent not obtained.

c) Children who were referred to our institute. There is no proper referral system operating in this area and those with a referral note would have invariably received treatment more than one health facility before being referred;
After being registered into the study, each child was thoroughly examined for all the conditions included in the IMCI algorithm, their disease classified, co-morbid conditions and the empirical treatment identified $[1,5]$. These were noted in a pre-prepared proforma. A complete medical history was obtained followed by a detailed clinical examination. After performing the necessary investigations, a diagnosis was made for each case. The child's nutritional status was assessed by using weight for age, under IAP classification. A classification of low weight was given to IAP Grades I \& II and of very low weight to IAP grade III \& IV. The presence of visible severe wasting or bipedal oedema along with skin changes or a combination of both was classified as severe malnutrition (Marasmus, Kwashiorkor or Marasmic Kwashiorkor) [7]. An attempt was made to identify the immunization status of each child, either by looking at their immunization card or by asking the parents or both. The cases were either advised home treatment and followed for 5 days or admitted to the ward and followed up for 5 days after discharge or were referred to other department in relevant cases. The admitted patients were managed according to the hospital management protocols and outpatients were managed according to the IMCI guidelines. Depending upon the severity of their illness, patients and their families were either given reassurance or symptomatic treatment plans as advised by IMCI approach [1,5,6].

Among the data noted were the presence of general danger signs, the symptoms with which each patient presented and the duration of symptoms, disease classification of the six conditions covered in IMCI i.e. pneumonia, diarrhoea, measles, fever, ear infection and nutritional status, immunization status of the child, presence of any other associated conditions that were not included in the IMCI, the care that the patient received, duration of hospital stay and the outcome of treatment. After collecting the necessary information the patient data was systematically compiled and classified into a case analysis sheet, using a coding system developed for this purpose. This data was then used for statistical analysis using SPSS software version 16.

\section{Results}

A total of 3,200 children attending the outpatient clinic were evaluated, among them 1,040 (35.6\%) children were hospitalized and $2,160(64 \%)$ were treated as outpatients or referred and followed up (Table 1). The majority of children, nearly two thirds, had two or more co-existent morbidities. The mean number of co-morbidities among the total cases, inpatients and outpatients were 1.76, 1.91 and 1.67 respectively. The co-existence of morbidities was significantly higher in those children, who had been assessed to have a relatively severe condition.

Table 1: Demographic characteristic of the population.

\begin{tabular}{|c|c|c|c|}
\hline Age/ Group & $\mathbf{6}$ months - 1 year & 1 year - 5 years & Total \\
\hline Male & 604 & 1122 & 863 \\
\hline Female & 522 & 952 & 737 \\
\hline
\end{tabular}


Male children composed $54 \%$ of the total population. The overall admission rate was $35.6 \%$ with $47.08 \%$ in children of 6 months - 1 year age and $31.42 \%$ in the 1 year - 5 year old age group. The most common complaint with which the child was brought to the hospital was fever, in 1,892 (59.12\%) patients. The second most common complaint was cough and / or difficult breathing (Table 2).

Table 2: The frequency of various symptoms and signs pertaining to the various diseases studied.

\begin{tabular}{|c|c|}
\hline General Danger Signs & 228 \\
\hline Fever & 1,892 \\
\hline Cough and / or difficult/ breathing/ grunting & 1,020 \\
\hline Vomiting and / or ear discharge & 528 \\
\hline Measles & 10 \\
\hline Ear pain and/ or ear discharge & 82 \\
\hline Skin problems & 282 \\
\hline Worm infestations & 108 \\
\hline Burning micturition & 36 \\
\hline Accidents & 62 \\
\hline Injuries & 26 \\
\hline Animal bites & 14 \\
\hline Poisoning & 22 \\
\hline Surgical conditions & 52 \\
\hline Other & 50 \\
\hline
\end{tabular}

The most common etiology for fever was acute respiratory infection followed by infectious diarrhoea. In 160 cases with fever either the cause of fever could not be determined or there were associated conditions like skin problems, worm infestations, ear infections or other surgical conditions (Table 3).

Out of the total treated outpatients, the most common cause was acute respiratory infection (ARI) followed by diarrhoea (Table 4). The ARI patients were typically treated with cotrimoxazole, in the older patients and amoxicillin in the younger patients. Children presenting with diarrhoea were advised to consume fluids and ORS at home, according to plan A and B of WHO. In the outpatient cohort, 778 children had diagnoses which are included in the IMCI with viral fever being the most common reported. (Table 5).

In the inpatient cohort, the most common diagnosis was pneumonia followed by dehydration (Table 6). In the inpatient cohort 232 children had diagnoses which are included in the IMCI, with nephrotic syndrome being most common (Table 7).
Of the 3,200 children studied, 2,184 (68.3\%) had normal nutritional status and 1,016 (31.7\%) suffered various degrees of malnutrition. Three hundred and four $(9.5 \%)$ patients had anaemia of moderate ( $\mathrm{Hb} \% 5$ to $7.9 \mathrm{gm}$. \%) or severe (Hb\% less than 5 gms \%) degree. Of the 32 patients with severe anaemia, 8 were associated with malaria, 6 were due to thalassemia, 8 were associated with worm infestations and the remainder had nutritional anaemia.

Regarding immunization status, 74 (2.31\%) children received no immunizations at all, 448 children (14\%) received only partial immunization or their immunization status could not be identified. Immunization was appropriate for age in 2,678 $(83.7 \%)$ of children. The measles vaccine coverage in this study was $86.7 \%$.

Of the total cohort, $1,180(36.8 \%)$ presented with a single condition or diagnosis, while 2,020 (63.12\%) suffered from more than one condition. A single child suffered with malnutrition, requiring an integrated approach. The incidence of co-morbidity was more common in the inpatient group, with 812 (71. \%) of 1,140 children suffering with 2 or more conditions. Only 328 patients (29\%) in this group presented with a single condition. In the outpatient group the incidence of morbidity was $59 \%$ and $852(41.35 \%)$ presented with a single condition. The overall mortality rate in this study was $1 \%$ with pneumonia being the most common cause of death.

Table 3: Distribution of etiology of fever in the study population.

\begin{tabular}{|c|c|c|}
\hline Diagnosis & No. of cases & Percentage \\
\hline Total no. of cases with fever & 1,892 & $100 \%$ \\
\hline Acute respiratory infections & 1020 & $53.91 \%$ \\
\hline Malaria & 108 & $5.71 \%$ \\
\hline Meningitis & 38 & $2.01 \%$ \\
\hline Diarrhea & 252 & $13.31 \%$ \\
\hline Dysentery & 20 & $1.05 \%$ \\
\hline Measles & 10 & $2.53 \%$ \\
\hline Infective hepatitis & 16 & $0.85 \%$ \\
\hline UTI & 36 & $1.9 \%$ \\
\hline Viral fever & 160 & $8.46 \%$ \\
\hline Typhoid & 72 & $3.81 \%$ \\
\hline Sepsis & 16 & $0.84 \%$ \\
\hline Others & 144 & $7.61 \%$ \\
\hline
\end{tabular}


Table 4: Various diagnosis of out-patient between 6 months to 5 years during study.

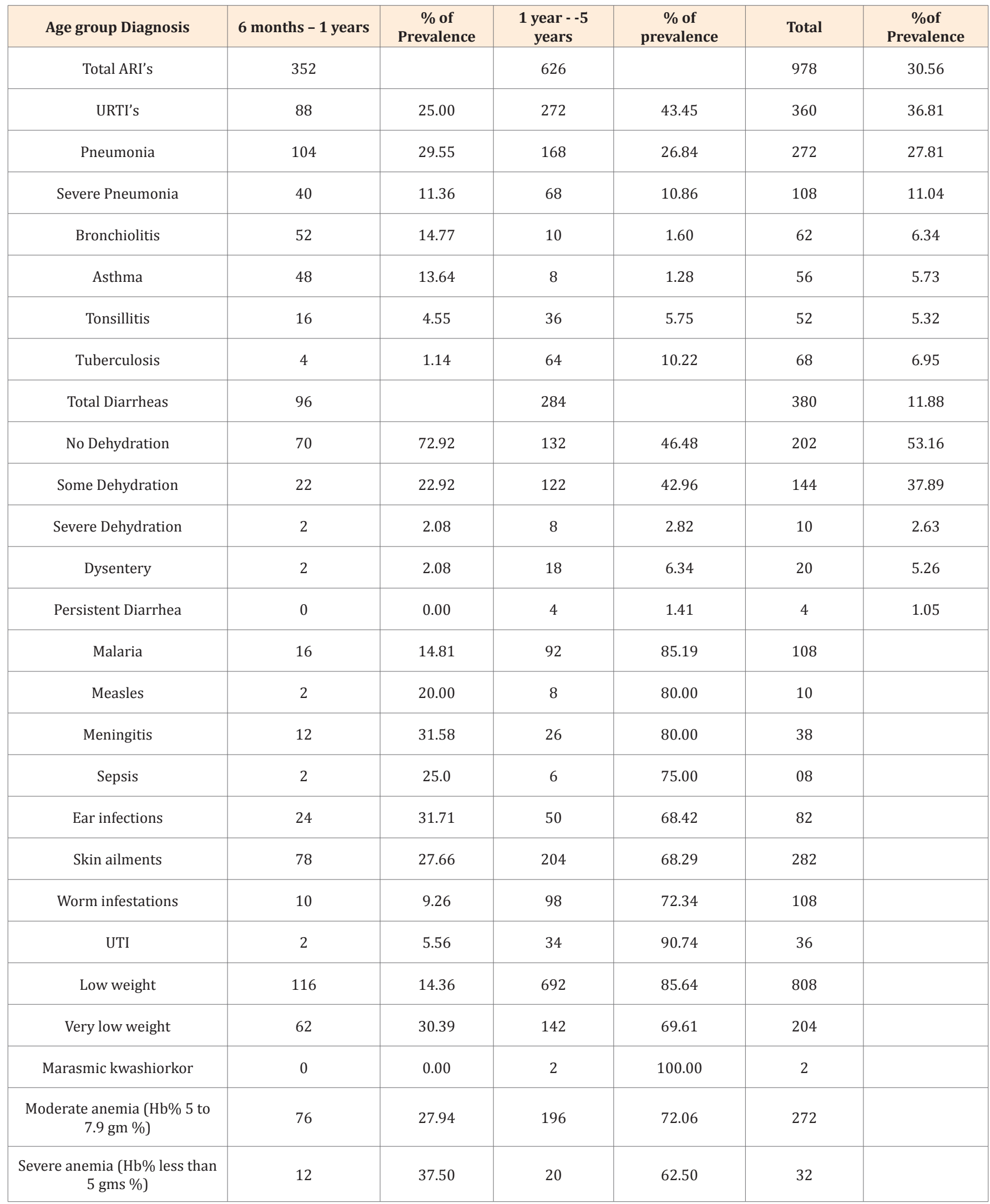

Citation: Mustafa SE, Pandita A, Sharma D, Yachha M, Pujari S (2016) A Hospital Based Prospective Observational Cross Sectional Study from India to Evaluate the Role of Integrated Management of Childhood Illness (IMCI) in under Five Childhood Illnesses (6 Months to 5 Years). J Pediatr Neonatal Care 4(5): 00151. DOI: 10.15406/jpnc.2016.04.00151 
Table 5: Diagnosis of the aliments that are not included in IMCI of the outpatient treated children's from 6 month to 5 years of age.

\begin{tabular}{|c|c|}
\hline Cerebral palsy & 36 \\
\hline Development delay & 32 \\
\hline Epilepsy & 10 \\
\hline Congenital heart disease & 24 \\
\hline Nephritic syndrome & 56 \\
\hline Acute Gastritis & 108 \\
\hline Appendicitis & 22 \\
\hline Calculus & 26 \\
\hline Kerosene poisoning & 0 \\
\hline Animal bites & 14 \\
\hline Injuries & 26 \\
\hline Surgical Condition & 76 \\
\hline Viral fever & 160 \\
\hline Infective hepatitis & 16 \\
\hline Mumps & 2 \\
\hline Chicken pox & 4 \\
\hline Bitot's spots/ Vitamin A deficiency & 4 \\
\hline Rickets & 8 \\
\hline Non-specific abdominal pain & 24 \\
\hline Dental carries & 6 \\
\hline Submandibular lymphadenitis & 4 \\
\hline Diabetes & 12 \\
\hline Accidents & 108 \\
\hline
\end{tabular}

Table 6: Various diagnosis of in-patient between 6 months to 5 years during study.

\begin{tabular}{|c|c|c|c|c|c|c|}
\hline Age group Diagnosis & $\begin{array}{c}6 \text { months - } \\
1 \text { years }\end{array}$ & $\begin{array}{c}\% \text { of } \\
\text { Prevalence }\end{array}$ & $\begin{array}{c}1 \text { year - -5 } \\
\text { years }\end{array}$ & $\begin{array}{c}\% \text { of } \\
\text { prevalence }\end{array}$ & Total & $\begin{array}{c}\% \text { of } \\
\text { Prevalence }\end{array}$ \\
\hline Total ARI's & 116 & & 164 & & 280 & 8.75 \\
\hline URTI's & 18 & 15.52 & 38 & 23.17 & 56 & 20 \\
\hline Pneumonia & 44 & 37.93 & 64 & 39.02 & 108 & 38.37 \\
\hline Severe Pneumonia & 46 & 39.66 & 8 & 4.88 & 54 & 19.28 \\
\hline Bronchiolitis & 8 & 6.90 & 28 & 17.07 & 36 & 12.85 \\
\hline Asthma & 8 & 6.90 & 28 & 17.07 & 36 & 12.85 \\
\hline Tonsillitis & - & - & 26 & 15.85 & 26 & 9.28 \\
\hline Tuberculosis & - & - & - & - & - & - \\
\hline Total Diarrhoeas & 16 & - & 64 & - & 80 & 2.5 \\
\hline
\end{tabular}

Citation: Mustafa SE, Pandita A, Sharma D, Yachha M, Pujari S (2016) A Hospital Based Prospective Observational Cross Sectional Study from India to Evaluate the Role of Integrated Management of Childhood Illness (IMCI) in under Five Childhood Illnesses (6 Months to 5 Years). J Pediatr Neonatal Care 4(5): 00151. DOI: 10.15406/jpnc.2016.04.00151 


\begin{tabular}{|c|c|c|c|c|c|c|}
\hline Some Dehydration & 6 & 75.00 & 29 & 62.50 & 26 & 32.5 \\
\hline Severe Dehydration & 2 & 25.00 & 8 & 25.00 & 10 & 12.5 \\
\hline Dysentery & - & - & - & 0.00 & - & - \\
\hline Persistent Diarrhoea & - & - & 4 & 12.50 & 4 & 5 \\
\hline Malaria & 4 & 16.67 & 20 & 83.33 & 24 & \\
\hline Measles & 2 & 20.00 & 8 & 80.00 & 10 & \\
\hline Meningitis & 12 & 31.58 & 26 & 68.42 & 38 & \\
\hline Sepsis & 02 & 25 & 06 & 75 & 08 & \\
\hline Ear infections & 4 & 22.22 & 14 & 77.78 & 18 & \\
\hline Skin ailments & 2 & 4.00 & 48 & 96.00 & 50 & \\
\hline Worm infestations & 6 & 14.29 & 36 & 85.71 & 42 & \\
\hline UTI & 2 & 20.00 & 8 & 80.00 & 10 & \\
\hline Low weight & 58 & 34.52 & 110 & 65.47 & 168 & \\
\hline Very low weight & 36 & 41.86 & 56 & 58.14 & 86 & \\
\hline Marasmic kwashiorkor & - & 0.00 & 2 & 100.00 & 2 & \\
\hline Moderate anemia ( $\mathrm{Hb} \% 5$ to $7.9 \mathrm{gm} \mathrm{\% )}$ & 34 & 26.56 & 94 & 73.44 & 128 & \\
\hline Severe anemia (Hb\% less than 5 gms \%) & 12 & 37.50 & 20 & 62.50 & 32 & \\
\hline
\end{tabular}

Table 7: Diagnosis of the aliments that are not included in IMCI of the inpatient treated children's from 6 month to 5 years of age.

\begin{tabular}{|c|c|}
\hline Cerebral palsy & 6 \\
\hline Development delay & 0 \\
\hline Epilepsy & 5 \\
\hline Congenital heart disease & 12 \\
\hline Nephritic syndrome & 28 \\
\hline Acute Gastritis & 11 \\
\hline Appendicitis & 0 \\
\hline Calculus & 11 \\
\hline Kerosene poisoning & 0 \\
\hline Animal bites & 0 \\
\hline Injuries & 0 \\
\hline Surgical Condition & 11 \\
\hline Viral fever & 18 \\
\hline Infective hepatitis & 0 \\
\hline Mumps & 0 \\
\hline Chicken pox & 0 \\
\hline Bitot's spots/Vitamin A deficiency & 0 \\
\hline Rickets & 1 \\
\hline Non-specific abdominal pain & 0 \\
\hline Dental carries & 0 \\
\hline Submandibular lymphadenitis & 0 \\
\hline Diabetes & 6 \\
\hline Accidents & 7 \\
\hline
\end{tabular}

Citation: Mustafa SE, Pandita A, Sharma D, Yachha M, Pujari S (2016) A Hospital Based Prospective Observational Cross Sectional Study from India to Evaluate the Role of Integrated Management of Childhood Illness (IMCI) in under Five Childhood Illnesses (6 Months to 5 Years). J Pediatr Neonatal Care 4(5): 00151. DOI: 10.15406/jpnc.2016.04.00151 


\section{Discussion}

With increasing awareness and continuing efforts initiated by the international community, the global burden of disease has been more effectively addressed in recent years. Since the 1970's childhood- illness are better managed by the perinatal care services and break through discoveries such as oral rehydration therapy which has revolutionized the management of childhood diarrhoea, ARI programmes, universal immunization programmes for vaccine preventable illness, various nutrition rehabilitation measures, have all made the world a safer place for children. Despite policy-makers increasingly concentrating on reduction of preventable causes of childhood mortality [8], 7 out of 10 children under the age of 5 years still die as a result of preventable and treatable conditions like pneumonia, diarrhoea, measles, malaria and malnutrition [9].

In this prospective observational study, 3,200 children attending the outpatient clinic department of Paediatrics in Shadan Institute of Medical Science, Hyderabad were included and analyzed for disease pattern, co-morbid conditions, nutritional and immunization status and outcomes. The utility of the IMCI approach in managing these patients was also assessed as part of the study. Of the 3,200 children, $35.6 \%$ were hospitalized and $64.4 \%$ treated as outpatients. This effectively reduced the admissions rate for those morbidities which can be managed using the IMCI format in an outpatient setting, thereby reducing the burden on health care personal which are already in limited in developing countries.

The most common symptom with which children presented was fever, with malaria being the most common cause $3.4 \%$. The high incidence of fever is expected given that fever is a common manifestation of various systemic infections Arifeen et al. reported in another study evaluated the effect of the Integrated Management of Childhood Illness strategy on childhood mortality and nutrition in a rural area in Bangladesh. This was a cluster randomised trial and they concluded that implementation of IMCI had led to improved health-worker skills, health-system support, and family and community practices, translating into increased care-seeking for illnesses. In IMCI areas, there was a larg percentage of exclusively breastfeed infants younger than 6 months and a reduction in malnutrition. In the last two years of this study there was also reduction of mortality [10].

In other study by Shah et al. they evaluated IMCI for childhood illness between the ages of two months to five years, they enrolled 203 children and found that more than one illness was present in $135(66.5 \%)$ of subjects. They concluded that there was a sound scientific basis for adopting the IMCI approach. There is usually co-existence of morbidities, with morbidities increasing with severity of illness, severe illness is assessed with good sensitivity and specificity; and the IMCI algorithm was diagnostically and therapeutically superior to the vertical disease specific algorithms [11]. The limitation of this study was small sample size. Our results are similar to this study. We also observed that the majority of patients could be effectively treated on an outpatient basis using IMCI protocols.

Gupta et al. in other study evaluated the IMCI approach in children between the ages of one week to two months. They enrolled 129 infants in their study and concluded that IMCI can be used effectively in young infants [12]. The limitation of t study was the small sample size. However, in our study we didn't included infants less than 6 months of age.

In a study conducted in Kenya to evaluate IMCI in areas with high malaria transmission, usefulness of IMCI algorithm was observed, but they insisted that performance of health workers need to be monitored during the early part of training [13]. In our study, we didn't involve untrained health care personal and everything was done by trained paediatricians, hence we were not able to assess the role of health care workers in our study.

There are many studies conducted in developing countries which have highlighted the importance of IMCI in management of childhood illness and reduction of mortality due to preventable causes [14-18]. Our study adds weight to the importance of IMNCI because we were able to reduce the hospital admission rate significantly. In a recently published meta-analysis importance of IMCI in management of childhood illness was emphasized and it was also concluded that health care personal need regular training for better implementation of the IMCI approach $[19,20]$.

\section{Strength of our study}

i. Study population was very large with different age groups.

ii. Evaluation of disease which are not included in IMCI.

iii. Large patient size treated in an outpatient department with follow up.

iv. Largest hospital based study reported thus far.

\section{Limitation of study}

I. The function of health care personal was not accessed as all the decisions were made by an trained doctor.

II. We didn't included infants less than 6 month of age.

\section{Conclusions}

Using the IMCI approach, significant reduction in hospitalization is possible which brings down the workload of already flooded hospitals with limited staff. Co-existence of morbidity was a rule rather than exception. On average, a child suffered 2 co-morbid conditions. The most common presenting complaint was fever. The majority of the conditions presenting in children under 5 years of age (85.2\%) are covered by IMCI guidelines. However skin problems and urinary tract infections need to be incorporated into the guidelines. Overall mortality rate was $1.2 \%$, most of which is easily preventable through better care management and immunization stressed in the IMCI algorithm.

\section{References}

1. Gove S, Tamburlini G, Molyneux E, Whitesell P, Campbell H (1999) Development and technical basis of simplified guidelines for emergency triage assessment and treatment in developing countries. WHO Integrated Management of Childhood Illness (IMCI) Referral Care Project. Arch Dis Child 81(6): 473-477.

2. Patwari AK, Raina N (2002) Integrated Management of Childhood Illness (IMCI) a robust strategy. Indian J Pediatr 69(1): 41-48.

3. Alkema L, Chao F, You D, Pedersen J, Sawyer CC (2014) National, regional, and global sex ratios of infant, child, and under-5 mortality and identification of countries with outlying ratios: a systematic assessment. Lancet Glob Health 2(9): e521-530. 
4. Liu L, Oza S, Hogan D, Perin J, Rudan I, et al. (2014) Global, regional, and national causes of child mortality in 2000-13, with projections to inform post-2015 priorities: an updated systematic analysis. Lancet 385(9966): 430-440

5. Gove S (1997) Integrated management of childhood illness by outpatient health workers: technical basis and overview. The WHO Working Group on Guidelines for Integrated Management of the Sick Child. Bull World Health Organ 75 (Suppl 1): 7-24.

6. Gove S (1997) Integrated management of childhood illness: conclusions. WHO Division of Child Health and Development. Bull World Health Organ 75 (Suppl 1): 119-128.

7. Mantan M, Bagga A (2011) Nutrition and Nutritional Disorders. In: Kabra SK, Srivastava SN (Eds.) Pediatrics: A Concise Text. New Delhi, India. Reed Elsevier Private Ltd pp. 47-60.

8. Das JK, Lassi ZS, Salam RA, Bhutta ZA (2013) Effect of community based interventions on childhood diarrhoea and pneumonia: uptake of treatment modalities and impact on mortality. BMC Public Health13 (Suppl 3): S29.

9. Bhutta ZA, Das JK, Walker N, Rizvi A, Campbell H, et al. (2013) Interventions to address deaths from childhood pneumonia and diarrhoea equitably: what works and at what cost? Lancet 381(9875): 1417-1429.

10. Arifeen SE, Hoque DME, Akter T, Rahman M, Hoque ME, et al. (2009) Effect of the Integrated Management of Childhood Illness strategy on childhood mortality and nutrition in a rural area in Bangladesh: a cluster randomised trial. Lancet 374(9687): 393-403.

11. Shah D, Sachdev HP (1999) Evaluation of the WHO/UNICEF algorithm for integrated management of childhood illness between the age of two months to five years. Indian Pediatr 36(8): 767-777.

12. Gupta R, Sachdev HP, Shah D (2000) Evaluation of the WHO/UNICEF algorithm for integrated management of childhood illness between the ages of one week to two months. Indian Pediatr 37(4): 383-390.
13. Perkins BA, Zucker JR, Otieno J, Jafari HS, Paxton L, Redd SC, et al (1997) Evaluation of an algorithm for integrated management of childhood illness in an area of Kenya with high malaria transmission. Bull World Health Organ 75 (Suppl 1): 33-42.

14. Armstrong Schellenberg JRM, Adam T, Mshinda H, Masanja H, Kabadi G, et al. (2004) Effectiveness and cost of facility-based Integrated Management of Childhood Illness (IMCI) in Tanzania. Lancet 364(9445): 1583-1594.

15. Armstrong Schellenberg J, Bryce J, de Savigny D, Lambrechts T, Mbuya C, et al. (2004) The effect of Integrated Management of Childhood Illness on observed quality of care of under-fives in rural Tanzania. Health Policy Plan 19(1): 1-10.

16. Arrivé E, Perez F, Pierre LMW (2004) The integrated management of childhood illness: Haiti's example. Santé 14(3): 137-142.

17. Huicho L, Dávila M, Campos M, Drasbek C, Bryce J, et al. (2005) Scaling up integrated management of childhood illness to the national level: achievements and challenges in Peru. Health Policy Plan 20(1): 14-24.

18. Huicho L, Dávila M, Gonzales F, Drasbek C, Bryce J, et al. (2005) Implementation of the Integrated Management of Childhood Illness strategy in Peru and its association with health indicators: an ecological analysis. Health Policy Plan 20 (Suppl 1): i32-i41.

19. Nguyen DTK, Leung KK, McIntyre L, Ghali WA, Sauve R (2013) Does integrated management of childhood illness (IMCI) training improve the skills of health workers? A systematic review and meta-analysis. PloS One 8(6): e66030.

20. Rowe AK, Rowe SY, Holloway KA, Ivanovska V, Muhe L, et al. (2012) Does shortening the training on Integrated Management of Childhood Illness guidelines reduce its effectiveness? A systematic review. Health Policy Plan 27(3): 179-193. 